\title{
Correction: A thyroid tumor extending to the parapharyngeal
}

\section{space}

\author{
Fikret Cetik*1, Demet Yazici ${ }^{1}$, Ramazan Gun ${ }^{1}$ and Aysun Uguz ${ }^{2}$
}

Address: ${ }^{1}$ Department of Otolaryngology, Cukurova University, Adana, Turkey and ${ }^{2}$ Department of Pathology, Cukurova University, Adana, Turkey

Email: Fikret Cetik* - mfcetik@gmail.com; Demet Yazici - demetyazici@yahoo.com; Ramazan Gun - remezanroj@yahoo.com; Aysun Uguz - aysunuz@yahoo.com

* Corresponding author

Published: 21 May 2007

BMC Ear, Nose and Throat Disorders 2007, 7:3 doi:10.1186/1472-6815-7-3
Received: 10 April 2007

Accepted: 21 May 2007

This article is available from: http://www.biomedcentral.com/1472-68/5/7/3

(c) 2007 Cetik et al; licensee BioMed Central Ltd.

This is an Open Access article distributed under the terms of the Creative Commons Attribution License (http://creativecommons.org/licenses/by/2.0), which permits unrestricted use, distribution, and reproduction in any medium, provided the original work is properly cited.

Although he was listed as an author in the original submission of an article published in BMC Ear, Nose and Throat Disorders by Cetik et al. [1], Dr Ramazan Gun was not included in the author list of the published version. The authors agree that Dr Gun meets the criteria for authorship, and should be considered to be an author of Cetik et al. 2006.

\section{References}

I. Cetik F, Yazici D, Uguz A: A thyroid tumor extending to the parapharyngeal space. BMC Ear Nose Throat Disord 2006, 6:3.

\section{Pre-publication history}

The pre-publication history for this paper can be accessed here:

http://www.biomedcentral.com/1472-6815/7/3/prepub 